|| ISSN(online): 2589-8698 || ISSN(print): 2589-868X || International Journal of Medical and Biomedical Studies

Available Online at www.ijmbs.info

PubMed (National Library of Medicine ID: 101738825)

Index Copernicus Value 2018: 75.71

Volume 3, Issue 4; April: 2019; Page No. 09-14

\title{
RAPID DETECTION OF FLUCONAZOLE RESISTANCE IN CANDIDA TROPICALIS BY MALDI- TOF-MS
}

\author{
Shivi Saxena, Rupal Sengar \\ Assistant Professor, Jayoti Vidyapeeth Women's University Jaipur, faculty of Physiotherapy \& \\ Diagnostics \\ Article Info: Received 18 February 2019; Accepted 02 April. 2019 \\ Cite this article as: Saxena, S., \& Sengar, R. (2019). RAPID DETECTION OF FLUCONAZOLE RESISTANCE IN \\ CANDIDA TROPICALIS BY MALDI-TOF-MS. International Journal of Medical and Biomedical Studies, 3(4). \\ DOI: https://doi.org/10.32553/ijmbs.v3i3.141 \\ Address for Correspondence: Shivi Saxena, Assistant Professor, Jayoti Vidyapeeth Women's University Jaipur, \\ faculty of Physiotherapy \& Diagnostics \\ Conflict of interest: No conflict of interest.
}

\section{Abstract}

The study of disease transmission and development of antifungal opposition among Candida species, rapid antifungal susceptibility testing (AFST) is essential for streamlining of antifungal treatment. This investigation was directed to institutionalize a matrix-assisted laser desorption ionization-time of flight mass spectrometry (MALDI - TOF MS) based AFST strategy (ms- AFST) for helplessness of Candida tropicalis detaches. Clinical secludes of $C$. tropicalis were affirmed for fluconazole obstruction by the CLSI (M27-A3) strategy. The incubation period and medication concentration were advanced to decide the insignificant profile change concentration (MPCC) by MALDI-TOF MS. The information were broke down first by direct visual perception of the spectra pursued by composite connection list (CCI) matrix investigation, virtual gel investigation, and group examination for affirmation. At long last, the connection between's minimum inhibitory concentrations (MICs) and MPCCs was assessed. A sum of 14 fluconazole resistance (MICs extending from 15 to $127 \mu \mathrm{g} / \mathrm{ml}$ ) and 18 fluconazole subseptible $C$. tropicalis segregates ( $\mathrm{MIC} \leq 1 \mu \mathrm{g} / \mathrm{ml}$ ) were incorporated into this examination. All C. tropicalis separates had noteworthy otherworldly changes after $4 \mathrm{~h}$ concentration with fluconazole. Of 33 confines, MPCCs what's more, MICs were equal for 15 disengages, and the MPCC was one weakening lower than the particular MIC in the rest of the 17 secludes. This finding was additionally upheld by visual investigation, $\mathrm{CCl}$ framework examination, virtual gel and chief part examination dendrogram investigation. The relationship among's MPCC and MIC was huge $(P<.05)$. In this way, a MALDI-TOF MS based AFST examine might be utilized as a fast screening procedure for fluconazole against in $C$. tropicalis.

Key words: matrix assisted laser desorption ionization-time of flight mass spectrometry, composite correlation index, principal component analysis, Candida tropicalis.

\section{Introduction:}

Candida species are the commonest specialists causing intrusive parasitic contaminations in people. Already, Candida albicans was considered as the transcendent pathogen be that as it may, non-Candida albicans Candida (NCAC) species have risen as the prevalent pathogens in Asian nations. ${ }^{\mathbf{1}, \mathbf{2}}$ In India, Candida tropicalis is the commonest specialist pursued by C. albicans, $C$. krusei, C. parapsilosis, and C. glabrata in candidemia patients. ${ }^{1}$ The changing the study of 
disease transmission of Candid contamination is incompletely credited to the abuse and abuse of antifungal medications particularly fluconazole. ${ }^{2,3}$ Several investigations from India have revealed rise of azole obstruction in purported powerless C. albicans and $C$. tropicalis. ${ }^{1} \quad$ Both Clinical and Laboratory Standards Institute (CLSI) and European Committee on Antibiotic Susceptibility Testing (EUCAST) affirmed juices microdilution (BMD) strategies for antifungal vulnerability testing for Candida species. ${ }^{4-} 6$ The assurance of least inhibitory focuses (MICs) by these techniques are tedious and may change among various settings. ${ }^{7,8}$ Other strategies including E-test, Sensititre, what's more, Vitek-2 are likewise accessible for antifungal susceptibility testing (AFST) yet may not correspond well with the reference standard methods. ${ }^{9}$ In vivo models were additionally produced for deciding MICs yet neglect to connect with in vitro methods. ${ }^{10} \mathrm{~A}$ straight forward, fast, and financially savvy technique like network helped laser desorption ionization-time of flight mass spectrometry (MALDITOF MS) based antifungal susceptible testing (ms- AFST) might be utilized to approve the customary AFST strategies.

Matrix-assisted laser desorption ionization-time of flight mass spectrometry is a rising strategy in clinical microbiology for quick distinguishing proof of clinical pathogens. ${ }^{11,12}$ However, with the rise of medication obstruction in microorganisms, AFST is urgent for advancement of treatment. A few examinations revealed the utilization of MALDI TOF-MS based antimicrobial vulnerability testing in microbes. ${ }^{13-15}$ But the clinical utilization of this procedure for routine AFST isn't approved right now. An examination by De Carolis et al. revealed the utilization of a ms-AFST for recognizable proof of caspofunginsafe separates of Candida what's more, Aspergillus by a composite connection record (CCI) approach. ${ }^{16}$ Similar investigations likewise detailed the identification of fluconazole and triazole opposition in Candida by ms-AFST. ${ }^{17,18}$ More examinations are required to approve what's more, improve this novel procedure. In this examination, we assessed the ms-AFST technique for distinguishing proof of fluconazole against among $C$. tropicalis clinical safe disconnects.

\section{METHODS:}

Yeast disconnects and antifungal susceptibility testing (AFST) The safe and vulnerable clinical isolates of $C$. tropicalis were acquired from National Culture Collection of Pathogenic Fungi (NCCPF), Chandigarh, India (www.nccpf.com). The segregates were resuscitated on Sabouraud dextrose agar (SDA; Himedia India) and were reconfirmed for azole resistance by disk diffusion method according to CLSI convention M44-A2. ${ }^{4}$ The outcome was additionally affirmed by the BMD strategy (M27-A3) as indicated by standard CLSI rules. The cut-off MIC values for helpless and safe segregates were resolved according to the M27-S3 interpretive rules of CLSI. ${ }^{6}$ In brief, the cell tally was balanced to $1 \times 106$ to $5 \times 106$ $\mathrm{cfu} / \mathrm{ml}$ spectrophotometrically at an optical thickness of $0.08-0.12$ at $529 \mathrm{~nm}$. Fluconazole stock $(12.8 \mathrm{mg} / \mathrm{ml})$ solution was utilized for dilution of drugs. Drug concentration extending from 127 to $0.124 \mu \mathrm{g} / \mathrm{ml}$ was utilized for vulnerability testing. A half restraint in development in contrast with a development control was noted as the MIC after $24 \mathrm{~h}$ brooding. Candida parapsilosis (ATCC 22019) furthermore, Candida krusei (ATCC 6258) were utilized as quality control strains. Streamlining of incubation period and drug concentration to decide the minimal profile change concentration (MPCC) One every one of safe (NCCPF-420193) and susceptible isolates (NCCPF-420203) were utilized for beginning standardization of MPCC by MALDI-TOF MS. In a word, crisp development of C. tropicalis was immunized in yeast separate peptone dextrose (YPD) juices (Himedia) and brooded medium-term in a shaker at $37 \circ \mathrm{C}$. One $\mathrm{ml}(1 \times 106$ cells $/ \mathrm{ml})$ from the medium-term development was then moved into a 250-ml conelike jar containing $30 \mathrm{ml}$ YPD broth. ${ }^{17}$ The way of life were uncovered at groupings of fluconazole going from 0.124 to $127 \mu \mathrm{g} / \mathrm{ml}$. One 
untreated culture was utilized as control. The societies were brooded at $37 \circ \mathrm{C}$ and reaped at 2 , $4,8,12,16$, and $20 \mathrm{~h}$ interims. Cell pellets acquired by centrifugation at $13,000 \mathrm{rpm}$ were at that point exposed to protein extraction pursued by MALDI-TOF MS investigation. Spectra were caught and examined for each strain under various culture conditions, that is, brooding periods and medication concentrations. ${ }^{16}$ Test arrangement for MALDI-TOF MS examination Both on-plate and off-plate extraction strategies were utilized for test arrangement of MALDITOF MS. The protein was removed from organisms as indicated by the method depicted from our laboratory. ${ }^{11}$

\section{MALDI-TOF MS estimation}

A Microflex LT Biotyper instrument (Bruker Daltonics, Bremen, Germany) was utilized for MALDI-TOF MS examination. Bruker suggested bacterial test standard (BTS 8255343) was utilized to align the instrument. As the most unmistakable, clear and noteworthy spectra lie in a mass scope of 5000 to $10000 \mathrm{~m} / \mathrm{z}$, protein mass spectra of tests were obtained by Flex Control 3.4 programming (Bruker Daltonics) in the previously mentioned locale. Laser recurrence for each run was $60 \mathrm{~Hz}$ with a direct positive mode. The default settings of the MALDI-TOF MS instrument were as pursues: focal point; $8.5 \mathrm{kV}$, particle source 1; $20 \mathrm{kV}$ and particle source 2; $18.1 \mathrm{kV}$. Flex control programming naturally procured the range of each spot. Every range was created by 240 laser shots (40 laser shot strides at six haphazardly chose places of a solitary spot). The quality of raw spectra was investigated by Flex Analysis 3.0 programming (Bruker Daltonics), furthermore, every range produced was broke down specifically against reference spectra. Further information were investigated by MALDI Biotyper 3 programming (Bruker Daltonics MC, Italy). ${ }^{\mathbf{1 1}}$ Negligible profile change fixation identification by MALDI-TOF MS.

MPCC is the minimum drug (fluconazole) concentration at which the mass spectra profile/unique mark changes. Visual investigation techniques were utilized for the recognition of MPCC by MALDI-TOF MS. The procured spectra were in this way transferred to Flex Analysis programming in MALDI TOF Biotyper what's more, outwardly broke down subsequent to smoothing and baseline subtractions. ${ }^{16}$ The visual investigation examination of MPCC was applied to all isolates after initial standardization.

Programming based investigation The finding of the visual investigation strategy was further affirmed by three programming based investigations: $\mathrm{CCl}$ matrix analysis, virtual gel examination, and cluster analysis. To total things up, $\mathrm{CCl}$ framework examination was executed as pursues. Flex control programming was set in mass scope of 5000 to $10000 \mathrm{~m} / \mathrm{z}$ to accomplish uniform spectra and to dodge the block from undesirable spectra. Procured spectra were along these lines broke down by the instrument in the MALDI Biotyper programming to decide composite relationship record $(\mathrm{CCl}){ }^{13}$ The $\mathrm{CCl}$ network was utilized to decide the connection between procured spectra measurably.

\section{RESULTS}

An aggregate of 34 isolates were tested by disk diffusion method; 13 were found resistant, two susceptible dose dependent (SDD), and 19 susceptible against fluconazole. Susceptibility profiles of these 34 strains were additionally affirmed by the CLSI BMD technique, and those 13 isolates were reconfirmed as safe against fluconazole with MICs extending from $16 \mu \mathrm{g} / \mathrm{ml}$ to $128 \mu \mathrm{g} / \mathrm{ml}$. Two SDD isolates by the disc diffusion method were observed to be safe by the BMD technique. Out and out, 15 safe and 19 vulnerable secludes were examined all through the examination. MPCC assurance by MALDI TOF MS In visual investigation examination, both the safe (NCCPF- 420193) and defenseless confines (NCCPF-420203) appeared unearthly changes after $4 \mathrm{~h}$ when tested with $128 \mu \mathrm{g} / \mathrm{ml}$ furthermore, $1 \mu \mathrm{g} / \mathrm{ml}$ fluconazole, separately. On looking at MPCC results with individual MICs, ghastly changes were seen in both resistant and 
susceptible isolates in correlation with the untreated control. Of the 15 fluconazole safe disconnects, only MPCCs of four isolates were actually equivalent to MICs, while MPCCs of 11 disengages were one level lower to individual
MIC sedate fixations. In the event that of defenseless segregates, MPCCs for 11 out of 19 disengages coordinated with MICs, though eight separates had otherworldly changes at one weakening lower than their comparing MICs.

Table1. Antifungal disc diffusion and broth dilution susceptibility testing of Candida tropicalis resistant and susceptible strains

\begin{tabular}{|l|l|l|l|l|l|}
\hline \multirow{2}{*}{$\begin{array}{l}\text { NCCPF } \\
\text { no }\end{array}$} & $\begin{array}{l}\text { Disc diffusion } \\
\text { testing }\end{array}$ & susceptibility & \multicolumn{2}{|l|}{$\begin{array}{l}\text { Broth dilution antifungal } \\
\text { susceptibility testing }\end{array}$} & $\begin{array}{l}\text { MPCC } \\
(\boldsymbol{\mu g} / \mathrm{ml})\end{array}$ \\
\cline { 2 - 6 } & $\begin{array}{l}\text { Zone diameter } \\
(\mathbf{2 5} \boldsymbol{\mu g} / \text { disc) }\end{array}$ & Susceptibility & MIC $(\boldsymbol{\mu g} / \mathbf{m l})$ & Susceptibility & \\
\hline $\mathbf{4 2 0 1 8 2}$ & No zone & $\mathrm{R}$ & 16 & $\mathrm{R}$ & 32 \\
\hline $\mathbf{4 2 0 1 8 3}$ & No zone & $\mathrm{R}$ & 16 & $\mathrm{R}$ & 16 \\
\hline $\mathbf{4 2 0 1 8 4}$ & 12 & $\mathrm{R}$ & 32 & $\mathrm{R}$ & 16 \\
\hline $\mathbf{4 2 0 1 8 5}$ & 14 & $\mathrm{R}$ & 32 & $\mathrm{~S}$ & 8 \\
\hline $\mathbf{4 2 0 1 8 6}$ & 16 & $\mathrm{SDD}$ & 64 & $\mathrm{~S}$ & 0.5 \\
\hline $\mathbf{4 2 0 1 8 7}$ & No zone & $\mathrm{R}$ & 16 & $\mathrm{R}$ & 0.15 \\
\hline $\mathbf{4 2 0 1 8 8}$ & No zone & $\mathrm{R}$ & 64 & $\mathrm{R}$ & 16 \\
\hline $\mathbf{4 2 0 1 8 9}$ & 17 & $\mathrm{SDD}$ & 128 & $\mathrm{~S}$ & 0.5 \\
\hline $\mathbf{4 2 0 1 9 0}$ & 12 & $\mathrm{R}$ & 16 & $\mathrm{R}$ & 18 \\
\hline $\mathbf{4 2 0 1 9 1}$ & 16 & $\mathrm{SDD}$ & 64 & $\mathrm{~S}$ & 0.8 \\
\hline
\end{tabular}

MIC, minimum inhibitory concentration; MPCC, minimal profile change concentration detection; $R$, resistant; S, susceptible; SDD = susceptible-dose dependent.

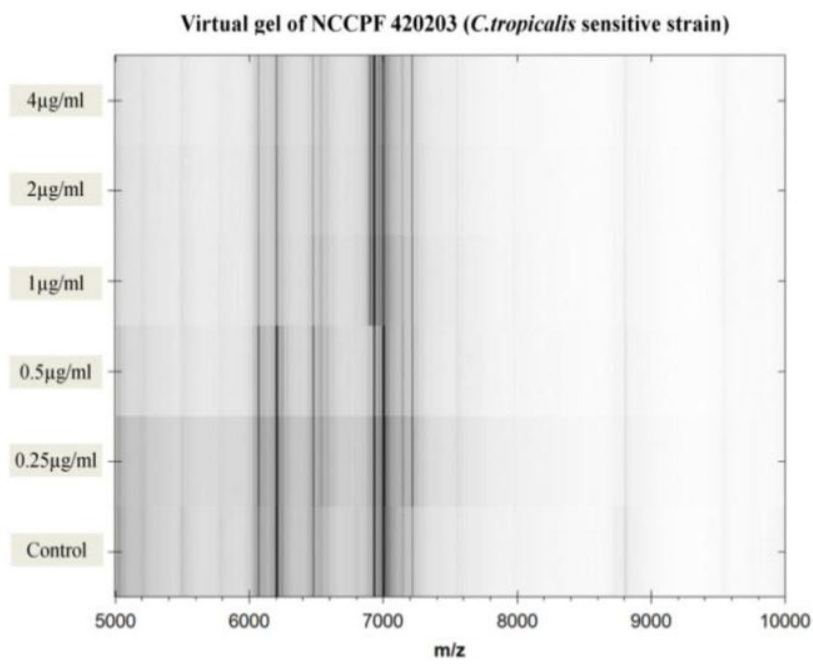

(a)

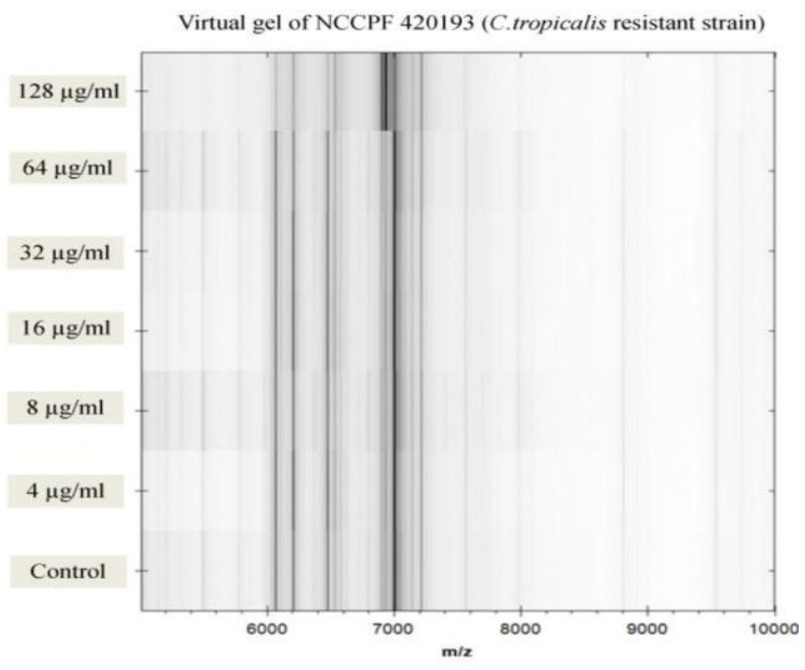

(b)

Figure 1: Virtual gel analysis by special tool in MALDI Biotyper 3 revealing changes in band pattern at MIC levels of $C$. tropicalis exposed to increasing concentration of fluconazole. $X$ axis represents the $\mathrm{m} / \mathrm{z}$ values and $y$ axis represents running spectra acquired at different drug concentration of fluconazole of (a) C. tropicalis susceptible (NCCPF 420203; MIC $1 \mu \mathrm{g} / \mathrm{ml}$ ) and (b) resistant (NCCPF 420193; MIC $127 \mu \mathrm{g} / \mathrm{ml}$ ) isolate. This Figure is reproduced in color in the online version of Medical Mycology. 


\section{CONCLUSION}

MALDI-TOF MS-based antimicrobial susceptibility testing is a novel approach and has been established for bacterial strains in a clinical setting. ${ }^{19-21}$ However, unlike bacteria, very few studies have evaluated the accuracy of ms-AFST in clinical laboratories. The resistant and susceptible $C$. tropicalis strains confirmed by BMD method were included for standardization of ms-AFST in this study.

\section{REFERENCES}

1. Chakrabarti A, Chatterjee SS, Rao KL et al. Recent experience with fungaemia: change in species distribution and azole resistance. Scand J Infec Dis. 2009; 41: 275-284.

2. Chakrabarti A, Mohan B, Shrivastava SK et al. Change in distribution \& antifungal susceptibility of Candida species isolated from candidaemiacases in a tertiary care centre during 1996-2000. Indian J Med Res. 2002;116: 5-12.

3. Chakrabarti A, Sood P, Rudramurthy SM et al. Incidence, characteristics and outcome of ICU-acquired candidemia in India. Intensive Care Med. 2015; 41: 285-295.

4. Method for Antifungal Disk Diffusion Susceptibility Testing of Yeasts; Approved Guideline, 2nd ed. CLSI M44-A2. Wayne, PA: Clinical and Laboratory Standards Institute, 2009.

5. Reference Method for Broth Dilution Antifungal Susceptibility Testing of Yeasts; 4th informational supplement. CSLI M27S4.Wayne, PA: Clinical and Laboratory Standards Institute, 2012.

6. Method for Broth Dilution Antifungal Susceptibility Testing of Yeasts, $3^{\text {rd }}$ ed. Approved Standard M27-A3. Wayne, PA: Clinical and Laboratory Standards Institute, 2008.

7. Lass-Florl C, Mayr A, Perkhofer S et al. Activities of antifungal agents against yeasts and filamentous fungi: assessment according to the methodology of the European
Committee on Antimicrobial Susceptibility Testing. Antimicrob. Agents Chemother. 2008; 52: 3637- 3641.

8. Revankar SG, KirkpatrickWR, McAtee RK et al. Interpretation of trailing endpoints in antifungal susceptibility testing by the National Committee for Clinical Laboratory Standards method. J Clin Microbiol. 1998; 36: 153-156.

9. Cuenca-Estrella $M$, Gomez-Lopez $A$, Alastruey-Izquierdo $A$ et al. Comparison of the Vitek 2 antifungal susceptibility system with the clinical and laboratory standards institute (CLSI) and European Committee on Antimicrobial Susceptibility Testing (EUCAST) Broth Microdilution Reference Methods and with the Sensititre YeastOne and Etest techniques for in vitro detection of antifungal resistance in yeast isolates. J Clin Microbiol. 2010; 48: 1782-1786.

10. Pfaller MA, Diekema DJ, Sheehan DJ. Interpretive breakpoints for fluconazole and Candida revisited: a blueprint for the future of antifungal susceptibility testing. Clin Microbiol Rev. 2006; 19: 435-447.

11. Ghosh AK, Paul S, Sood $P$ et al. Matrixassisted laser desorption ionization time-offlight mass spectrometry for the rapid identification of yeasts causing bloodstream infections. Clin Microbiol Infect. 2015; 21: 372-378.

12. Panda A, Ghosh AK, Mirdha BR et al. MALDITOFmass spectrometry for rapid identification of clinical fungal isolates based on ribosomal protein biomarkers. J Microbiol Methods. 2015; 109: 93-105.

13. Sparbier K, Lange $C$, Jung J et al. MALDI biotyper-based rapid resistance detection by stable-isotope labeling. J Clin Microbiol. 2013; 51: 3741- 3748.

14. Sparbier K, Schubert S, Weller $U$ et al. Matrix-assisted laser desorption ionizationtime of flight mass spectrometry-based functional assay for rapid detection of resistance against beta-lactam antibiotics. J Clin Microbiol. 2012; 50: 927-937. 
15. Vella A, De Carolis $E$, Vaccaro $L$ et al. Rapid antifungal susceptibility testing by matrixassisted laser desorption ionization-time of flight mass spectrometry analysis. J Clin Microbiol. 2013; 51: 2964-2969.

16. De Carolis E, Vella A, Florio AR et al. Use of matrix-assisted laser desorption ionizationtime of flight mass spectrometry for caspofungin susceptibility testing of Candida and Aspergillus species. J Clin Microbiol. 2012; 50: 2479-2483.

17. Marinach C, Alanio A, Palous Met al. MALDITOF MS-based drug susceptibility testing of pathogens: the example of Candida albicans and fluconazole. Proteomics. 2009; 9: 46274631.

18. Saracli MA, Fothergill AW, Sutton DA et al. Detection of triazole resistance among Candida species by matrix-assisted laser desorption/ionization-time of flight mass spectrometry (MALDI-TOF MS). Med Mycol. 2015; 53: 736-742.

19. Burckhardt I, Zimmermann S. Using matrixassisted laser desorption ionization-time of flight mass spectrometry to detect carbapenem resistance within 1 to 2.5 hours. J Clin Microbiol. 2011; 49: 3321-3324.

20. Griffin PM, Price GR, Schooneveldt JM et al. Use of matrix-assisted laser desorption ionization-time of flight mass spectrometry to identify vancomycin-resistant enterococci and investigate the epidemiology of an outbreak. J Clin Microbiol. 2012; 50: 29182931.

21. Majcherczyk PA, McKenna T, Moreillon P et al. The discriminatory power of MALDI-TOF mass spectrometry to differentiate between isogenic teicoplanin-susceptible and teicoplanin-resistant strains of methicillin resistant Staphylococcus aureus. FEMS Microbiol Lett. 2006; 255: 233-239 